\title{
Costs for Integrating Wind into the Future ERCOT System with Related Costs for Savings in V(CO_2V) Emissions
}

\section{Citation}

Lu, Xi, Michael B. McElroy, and Nora A. Sluzas. 2011. Costs for integrating wind into the future ERCOT system with related costs for savings in \(CO_2 $)$ emissions. Environmental Science and Technology 45(7): 3160-3166.

\section{Published Version}

doi: 10.1021/es103948t

\section{Permanent link}

http://nrs.harvard.edu/urn-3:HUL.InstRepos:10001143

\section{Terms of Use}

This article was downloaded from Harvard University's DASH repository, and is made available under the terms and conditions applicable to Open Access Policy Articles, as set forth at http:// nrs.harvard.edu/urn-3:HUL.InstRepos:dash.current.terms-of-use\#OAP

\section{Share Your Story}

The Harvard community has made this article openly available.

Please share how this access benefits you. Submit a story.

\section{Accessibility}


Title:

\title{
Costs for integrating wind into the future ERCOT system with related costs for savings in $\mathrm{CO}_{2}$ emissions
}

\author{
Author Affiliation: \\ Xi Lu \\ School of Engineering and Applied Science, Harvard University \\ Cruft Lab 211, 19 Oxford St., MA 02138 \\ Michael B. McElroy* \\ School of Engineering and Applied Sciences and Department of Earth and Planetary Sciences, \\ Harvard University \\ 100G Pierce Hall, 29 Oxford St., MA 02138 \\ Nora Sluzas \\ Department in Environmental Science \& Public Policy, Harvard University \\ Cruft Lab 211, 19 Oxford St., MA 02138 \\ Corresponding Author: \\ Michael B. McElroy (mbm@seas.harvard.edu) \\ Number of Pages: 23 \\ Number of Figures: 5 \\ Number of Tables: 1 \\ Key words:
}

Inclusion of Wind in the ERCOT System | Variability of Wind | $\mathrm{CO}_{2}$ Savings and Costs 


\section{Abstract}

Wind power can make an important contribution to the goal of reducing emissions of $\mathrm{CO}_{2}$. The major problem relates to the intrinsic variability of the source and the difficulty of reconciling the supply of electricity with demand particularly at high levels of wind penetration. This challenge is explored for the case of the ERCOT system in Texas. Demand for electricity in Texas is projected to increase by approximately $60 \%$ by 2030. Considering hourly load data reported for 2006 assuming that the pattern of demand in 2030 should be similar to 2006 and adopting as a business as usual (BAU) reference an assumption that the anticipated additional electricity should be supplied by a combination of coal and gas with prices, discounted to 2007 dollars of $\$ 2$ and $\$ 6$ per MMBTU respectively, we conclude that the bus-bar price for electricity would increase by about $1.1 \mathrm{c} / \mathrm{kWh}$ at a wind penetration level of $30 \%$, by about $3.4 \mathrm{c} / \mathrm{kWh}$ at a penetration level of $80 \%$. Corresponding costs for reductions in $\mathrm{CO}_{2}$ range from $\$ 20 /$ ton to $\$ 60 /$ ton. A number of possibilities are discussed that could contribute to a reduction in these costs including the impact of an expanded future fleet of electrically driven vehicles.

\section{Introduction}

It is clear, as indicated in a number of recent studies (1-3) that wind has the potential to accommodate projected global demand for electricity for the foreseeable future. Archer and Jacobson (2), using data from 7,753 surface meteorological stations complemented by results from 446 stations for which vertical soundings were available, concluded that $20 \%$ of the global potential for wind could supply as much as 14 terawatts (TW) of electricity corresponding to 7 times total current demand. Lu et al(3) using wind fields derived from assimilation of meteorological data by the NASA Goddard Earth Observing System Data Assimilation System (GEOS-5 DAS), concluded that a global network of land-based 2.5-megawatt (MW) turbines restricted to non-forested, icefree, non-urban areas operating at as little as $20 \%$ of their rated capacity could supply 
more than 40 times total current global consumption of electricity (more than 5 times consumption of energy in all forms). They concluded in particular that wind could account for the bulk of electricity consumed presently by the top $10 \mathrm{CO}_{-}$-emitting countries (countries responsible for more than $64 \%$ of total global fossil fuel related emissions) (4).

While the wind resource is more than sufficient to satisfy requirements for electricity for most of the major electricity consuming countries on an annual basis, accommodating demand or load on shorter time scales poses a more serious challenge. Wind is intrinsically variable. Real time demand for electricity is often thus poorly matched with the potential supply from wind (5) . Over much of the U.S. for example, consumption of electricity tends to peak in summer responding to the requirement for air conditioning while the supply from wind is typically greatest in winter. Similarly, demand for electricity is normally greatest during the day while the potential supply from wind over land is typically highest at night in many locations.

This paper is intended to explore the implications of the potential mismatch between demand for electricity over a particular region and the supply available from wind. Costs for savings in emissions of $\mathrm{CO}_{2}$ are analyzed specifically for variable levels of wind-penetration with a focus on the future, complementing earlier work directed mainly at analysis of the existing power system (6-9) that mostly focus on modeling the existing systems. We choose as a specific case for study the region of Texas served by the Electricity Reliability Council of Texas (ERCOT) which manages delivery of electricity 
to 22 million consumers, accounting for $85 \%$ of demand for the state as a whole.

ERCOT is the smallest of the 3 interconnected electric grids in the United States. Largest is the Eastern interconnection accommodating requirements for $69 \%$ of the US population in the Eastern and Southern regions of the country while $23 \%$ is supplied through the Western Interconnection system. The ERCOT interconnection was selected for this study for two reasons: first, we had access to load data for the region on an hourly basis over a 5-year period; second, since wind conditions are expected to be highly correlated over the relatively limited geographic region served by ERCOT, we expect that the challenge of reconciling supply of electricity from wind with demand is likely to be more serious in this case than for either of the more extensive geographic regions served by the Eastern and Western Interconnections: low levels of wind in portions of these regions are more likely to be compensated by higher levels elsewhere (10-12).

\section{Data and Methodology}

The analysis will be based on a study of how different levels of wind penetration could be integrated into a system required to accommodate demand for electricity in real time on an hour-by-hour basis. We restrict attention here to five areas of west Texas, identified as Competitive Renewable Energy Zones (CREZ), selected in 2005 by the Public Utilities Commission (PUC) of Texas for preferential development of the state's wind resources. As indicated in SI, the CREZ include some of the most favorable conditions for wind in Texas. 
The analysis uses wind fields derived from reanalysis of meteorological data compiled for 2006 by the National Centers for Environmental Prediction (NCEP) of the National Oceanic and Atmospheric Administration (NOAA) (13). The data base, RUC-20, provides a record of wind speeds on an hourly basis with a spatial resolution of $20 \mathrm{~km}$ by $20 \mathrm{~km}$. Wind speeds at $100 \mathrm{~m}$, the hub height for the $2.5-\mathrm{MW}$ turbines considered here, were calculated on the basis of cubic spline interpolation of results for the lowest 5 layers of the record (See SI).

Results from the simulation are in excellent agreement with experience from wind farms currently operational in Texas. Approximately $2.7 \mathrm{GW}$ of wind capacity was available for Texas in 2006, distributed over 13 counties in the state. Figure 1 presents a comparison of simulated and observed outputs for the system for four representative weekly intervals in 2006. The correlation between observed and simulated results for the four seasons, winter (December-February), spring (March-May), summer (JuneAugust) and fall (September-November), amounted to $0.85,0.73,0.84$ and 0.88 respectively with an annual mean of 0.79 . The agreement is particularly impressive since the wind farms in the simulation were assumed to be distributed uniformly over the relevant counties while the actual farms were concentrated presumably in regions judged particularly favorable, and since the simulation was restricted to a study of the output of turbines with specific operational properties and capacities (2.5 MW). 

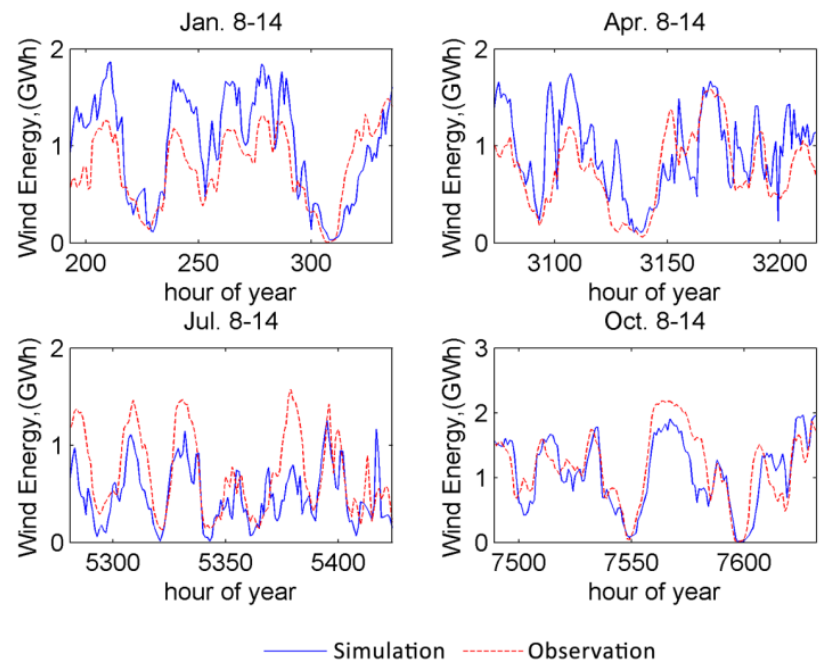

Figure 1 Comparison of simulated and observed outputs of wind power in Texas for seasonally representative weekly intervals in 2006. Potential outputs (blue curves) were scaled to provide the same annually integrated production as the observed (red curves).

Base load demand for electricity in ERCOT is supplied by a combination of nuclear and coal fired systems with load following systems fueled primarily by natural gas. In 2006, $46.3 \%$ of ERCOT electricity was produced using natural gas; coal, nuclear and wind accounted for $37.4 \%, 13.6 \%$ and $2.1 \%$ respectively with hydro and other minor sources responsible for the balance. The supply from wind increased by more than 200\% between 2006 and 2009 (Texas now has the largest installed capacity for wind of all of the states in the U.S., reflecting in large measure the incentives introduced by the PUC in 2005 to fund connections of new systems in CREZ to the existing grid).

Future demand for electricity in the ERCOT region is projected to grow at an annual rate of approximately $2 \%(14)$. This will require an increase in generating capacity of about $60 \%$ by 2030 relative to 2006 . We assume as a base case in what follows that this additional supply is produced by a price optimal combination of 
coal and gas fired systems identifying this reference as the business as usual (BAU) standard against which to compare alternative models incorporating different levels of production from wind. There are two objectives for the discussion that follows: one is to identify the additional costs incurred as wind substitutes progressively for coal and gas; the second is to estimate the savings in $\mathrm{CO}_{2}$ emissions that could be realized through a cost effective substitution of wind for coal and gas together with an estimate of the related costs. A more comprehensive analysis could attempt to account for the externality by costs (health and climate for example) associated with coal and gas. This would serve of course to enhance the advantage of wind $(15,16)$.

Costs for generation of electricity in the reference BAU system depend on a combination of fixed costs for capital and variable costs for operation. Capital costs are expected to be greatest for state-of-the-art coal fired systems (CFS), less for gas combined cycle systems (GCC) and lower still for gas combustion turbine systems (GCT). GCTs assumed here include reciprocating systems capable of rapid start-up. On the other hand, operational costs for CFS are lower than costs for GCC while costs for GCT are higher than costs for either CFS or GCC. A summary of cost data assumed for the different systems considered here is presented in Table 1(17) (See SI). 
Table 1 Cost parameters for future coal fired systems (CFS), gas combined cycle systems (GCC) and gas combustion turbine systems $(\mathrm{GCT}),(1 \mathrm{mill}=\$ 0.001)$.

\begin{tabular}{|c|c|c|c|c|}
\hline & $\begin{array}{c}\text { Capital cost } \\
\mathbf{( \$ / k W )}\end{array}$ & $\begin{array}{c}\text { Variable O\&M cost } \\
\text { (mills/kWh) }\end{array}$ & $\begin{array}{c}\text { Fixed O\&M cost } \\
\mathbf{( \$ / k W )}\end{array}$ & $\begin{array}{c}\text { Heat Rate } \\
\text { (BTU/kWh) }\end{array}$ \\
\hline CFS & 1,923 & 4.59 & 27.53 & 8,740 \\
\hline GCC & 877 & 2.00 & 11.7 & 6,333 \\
\hline GCT & 604 & 3.17 & 10.53 & 8,550 \\
\hline
\end{tabular}

Note:

1) Financial data quoted here and elsewhere in the paper are expressed in 2007 equivalent currency values.

2) Heat rate for GCT is expressed in terms of the lower heating value (LHV); data for CFS and GCC are given in terms of the higher heating value (HHV).

\section{Results and Discussion}

The optimal mix of generation systems can be identified using screening curves for the different generation systems (18) as indicated in Figure 2a. The vertical axis in Figure $2 \mathrm{a}$ identifies the revenue required to operate a particular system for a particular number of hours over the course of a year. The horizontal axis identifies the assumed number of full-capacity operational hours for each system. The intercept for the individual curves at the zero operational hour point is determined by the combination 
of the capital and fixed operational and maintenance (O\&M) costs. The slope of the individual curves reflects the combination of costs for fuel, the efficiency with which this fuel can be employed to generate electricity and the expense for O\&M. The analysis assumes a cost for coal of $\$ 2$ per million BTU (\$2/MMBTU), which may be compared with the cost of $\$ 1.6 / \mathrm{MMBTU}$ that pertained in 2006 (19). The cost for gas is taken as $\$ 6 / \mathrm{MMBTU}$, slightly lower than the 2006 cost of $\$ 6.4 / \mathrm{MMBTU}$ (prices for natural gas have declined in the US since 2006 with spot prices currently closer to \$4/MMBTU). The efficiency with which the energy of coal and gas can be converted to electricity is determined by the relevant heating rates, data for which are included in Table 1.

(a)

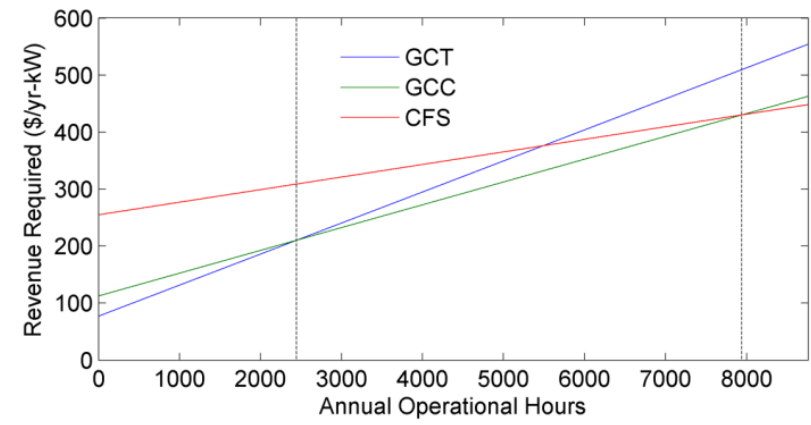

(b)

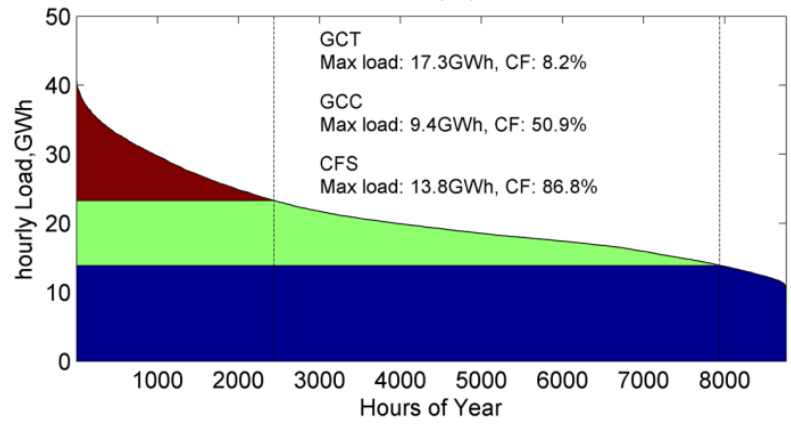

Figure 2 (a) Screening curves as discussed in the text for CFS, GCC and GCT; (b) contributions from CFS, GCC and GCT required to meet the additional load demand (ALD) projected for 2030 at minimum cost. 
The results in Figure $\mathbf{2} \mathbf{b}$ indicate that for CFS to be cost effective they must operate for close to 8000 full-capacity hours over the course of a year. GCC is more cost effective than CFS when the latter is operational for less than 8000 hours while GCT is most effective in meeting peak demand when operating for less than about 2400 fullcapacity hours over the course of a year. The cost optimal transitions from GCT to GCC and from GCC to CFS are indicated by the vertical lines in Figure $\mathbf{2 a}$.

The increase in the hourly load demand projected for 2030 is presented in Figure 2b. We assume here that the variation of additional load demand (ALD) with time in 2030 is similar to the pattern that pertained in 2006. The hourly ALD varies from a maximum of $40.6 \mathrm{GWh}$, in late summer evenings to a minimum of about $10.2 \mathrm{GWh}$, during night time hours in fall, winter and spring (See SI). In addition to the generating capacity needed to satisfy the demand as indicated in Figure $\mathbf{2} \mathbf{b}$, the system is required to maintain a reserve sufficient to accommodate unanticipated increases in load and/ or temporary losses of generating capacity. For ERCOT, this reserve is mandated at a level equal to no less than $12.5 \%$ of the total capacity of the system (5). We assume for purpose of the BAU model that this reserve is assigned to the individual components of the system (CFS, GCC and GCT) in proportion to their maximum load as indicated in Figure $\mathbf{2 b}$.

The results in Figure $\mathbf{2} \mathbf{b}$ indicate that least cost production of the additional electricity in the BAU model (allowing for reserve) would require generation capacities of $15.9 \mathrm{GW}, 10.7 \mathrm{GW}$ and $19.8 \mathrm{GW}$ for CFS, GCC and GCT respectively operating at CF 
values of $86.8 \%, 50.9 \%$ and $8.2 \%$ respectively. Maximum hourly outputs for CFS, GCC and GCT are estimated at $13.8 \mathrm{GWh}, 9.4 \mathrm{GWh}$ and $17.3 \mathrm{GWh}$ respectively. The average bus-bar price for electricity generated by the combined system (allowing for capacity imbedded in the reserve) is estimated at $6.2 \mathrm{c} / \mathrm{kWh}$, reflecting prices for CFS, GCC and GCT of $5.1 \mathrm{c} / \mathrm{kWh}, 6.2 \mathrm{c} / \mathrm{kWh}$ and $14.8 \mathrm{c} / \mathrm{kWh}$ respectively. By way of comparison, the bus-bar price for wind-generated electricity is taken as $7 \mathrm{c} / \mathrm{kWh}$ using data for existing wind farms as reported by Wiser and Bolinger (20).

Adding wind to the generation mix results in a steepening of the duration curve for hourly load demand as indicated for the BAU case in Figure $\mathbf{2 b}$. As discussed earlier, demand for electricity is greatest in summer when the supply from wind is generally at a minimum. It follows that the supply of electricity during hours of peak demand (the left hand portion of the curve in Figure $\mathbf{2 b}$ ) must continue to be met by the conventional coal-gas system. The contribution from wind is particularly important in winter when demand is at a seasonal minimum (impacting thus differentially the shape of the residual coal-gas curve to the right of the demand curve in Figure $\mathbf{2 b}$ ). As the supply of power from wind increases, the economic advantages of the source from CFS decrease. The resulting change in the mix of wind, CFS, GCC and GCT as constrained to supply electricity at minimum additional cost is illustrated in Figure 3a. Coal drops out of the mix as the penetration of wind increases above $30 \%$ on an annual basis. Requirements for standby gas systems to accommodate temporal deficiencies in the supply from wind increase accordingly adding additional expense to the system due to the resulting lower 
CF of the gas system. For penetration levels of wind greater than about $30 \%$, the source of power from wind is more than sufficient to meet demand, as indicated in the figure, resulting in a potential net increase in the supply of electricity relative to demand.

Increasing penetration of wind results in additional uncertainty in the power required to be supplied by the coal-gas system. Reserves must be increased accordingly: the higher the wind penetration, the greater the need for reserves to accommodate unanticipated shortfalls in the supply from wind. As discussed in SI, this reserve is estimated to increase from $12.5 \%$ in the low-wind BAU limit to as much as $30 \%$ at a wind penetration level of $80 \%$.

Addition of wind to the generation mix results in a decrease in emissions of $\mathrm{CO}_{2}$ relative to $\mathrm{BAU}$. The reduction in emissions is particularly significant at lower levels of wind penetration responding to differential displacement of coal relative to gas. At a penetration level of $30 \%$, wind is predicted to result in a $58.0 \%$ reduction of emissions of $\mathrm{CO}_{2}$ (equivalent to 81.2 million tons of $\mathrm{CO}_{2}$ per year). Reductions continue as coal is eliminated but at a slower rate reflecting the lower $\mathrm{CO}_{2}$ emission factors for $\mathrm{GCC}$ as compared to CFS. Emissions of $\mathrm{CO}_{2}$ as a function of wind penetration corresponding to the data in Figure $3 \mathbf{a}$ are presented in Figure 4a.

(a) Price Optimal 


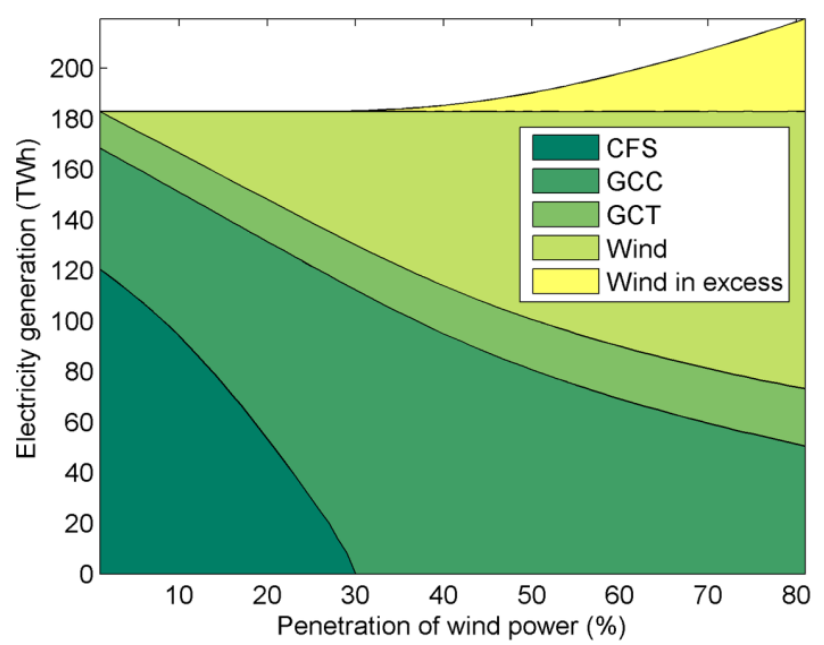

(b) $\mathrm{CO}_{2}$ Optimal

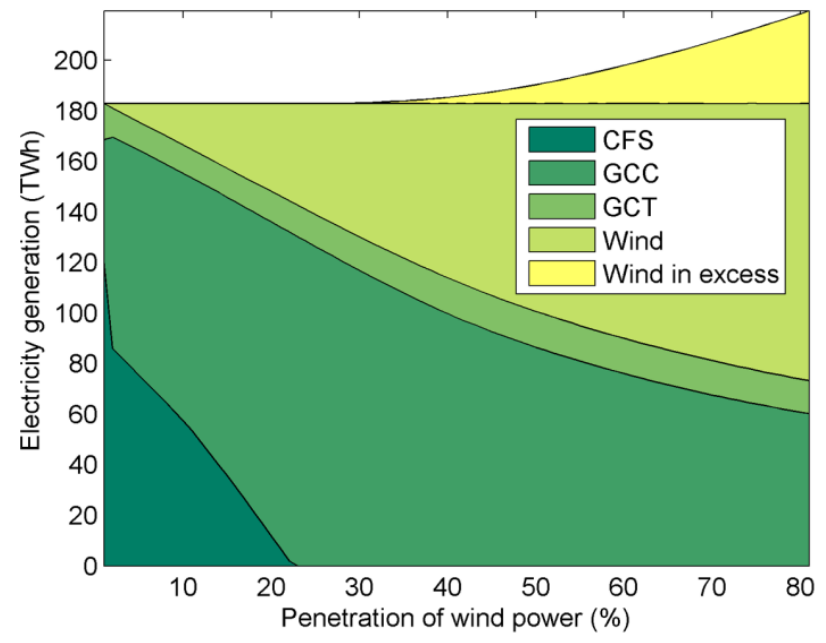

Figure 3 Changes in the mix of power generation as a function of wind penetration level. For further discussion of the price and $\mathrm{CO}_{2}$ optimal models, see text.

The results in Figures $\mathbf{3 a}$ and $\mathbf{4 a}$ were constrained to minimize the additional cost for electricity relative to BAU resulting from increasing penetration of wind. An alternate strategy would seek to identify the most cost effective way to maximize reductions in $\mathrm{CO}_{2}$. A displacement to the right of the $\mathrm{GCC} / \mathrm{CFS}$ transition in Figure $\mathbf{2 b}$ would result in a decrease in CFS relative to GCC with a corresponding reduction in emissions of $\mathrm{CO}_{2}$. The net cost for electricity would increase however since production from GCC is more expensive than production from CFS. There is an optimal 
displacement that would ensure maximum reduction of $\mathrm{CO}_{2}$ emissions at minimum cost. The resulting change in the mix of generation sources as a function of wind penetration for this least cost $\mathrm{CO}_{2}$ reduction scenario is presented in Figure $\mathbf{3 b}$. The corresponding change in emissions is illustrated in Figure $\mathbf{4 b}$. Emissions would be reduced by as much as $50.6 \%$ at a wind penetration level of $20 \%$, significantly larger than the reduction of $35.8 \%$ for the same penetration level in the price optimal model. The primary difference between the results in Figures $\mathbf{4 a}$ and $\mathbf{4 b}$ reflects the more rapid transition from CFS to GCC in the $\mathrm{CO}_{2}$ optimal model as compared to the price optimal model. Costs for $\mathrm{CO}_{2}$ reductions for the price optimal model and the $\mathrm{CO}_{2}$ optimal model are presented as functions of wind penetration in Figure 5a.

(a) Price Optimal

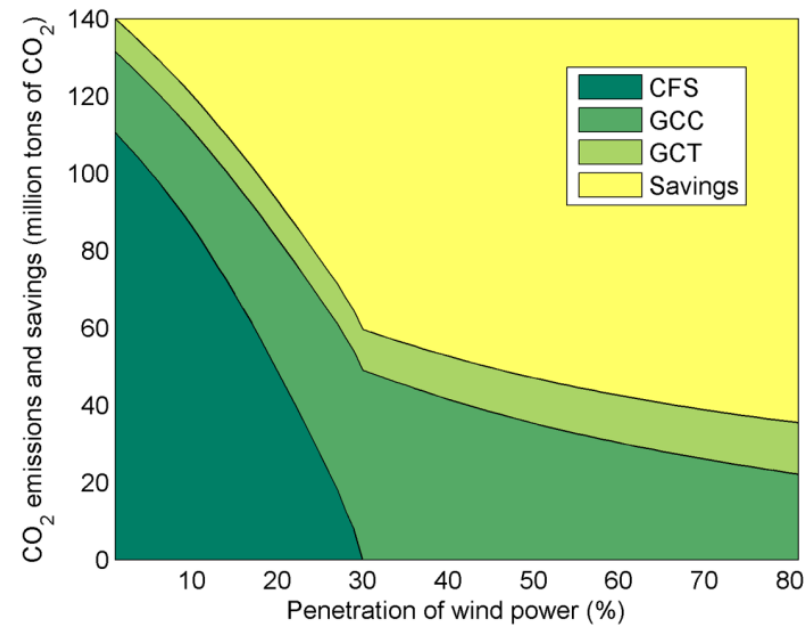

(b) $\mathrm{CO}_{2}$ Optimal 


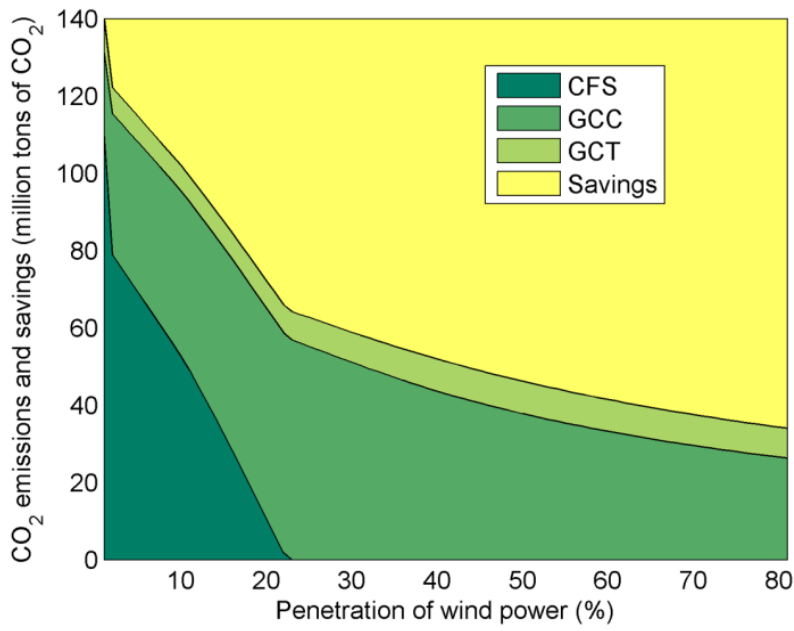

Figure 4 Changes in emissions of $\mathrm{CO}_{2}$ from CFS, GCC and GCT as a function of wind penetration level. Reductions in emissions are illustrated in yellow. For further discussion of the price and $\mathrm{CO}_{2}$ optimal models, see text.

Since the cost for electricity delivered by wind $(7 \mathrm{c} / \mathrm{kWh})$ is higher than the cost for power delivered either by coal or gas fired systems at low penetration levels for wind, the cost for electricity rises inevitably as wind begins to displace coal and gas. The increase in cost for the price optimal model is summarized in Figure $\mathbf{5 b}$. The increase amounts to $0.71 \mathrm{c} / \mathrm{kWh}$ at a wind penetration level of $20 \%$ rising to $1.1 \mathrm{c} / \mathrm{kWh}$ at a penetration level of $30 \%$. The cost for the CFS, GCC and GTS components at a wind penetration level of $20 \%$ average $5.29 \mathrm{c} / \mathrm{kWh}, 6.06 \mathrm{c} / \mathrm{kWh}$ and $15.07 \mathrm{c} / \mathrm{kWh}$ respectively. The increase in cost for the CFS (relative to the BAU reference of $5.14 \mathrm{c}$ / $\mathrm{kWh}$ ) reflects a reduction in the number of operational hours for this system. The decrease in the cost for power supplied by GCC at $20 \%$ wind relative to BAU $(0.15 \mathrm{c} /$ $\mathrm{kWh}$ ) is attributable to the increase in CF for this component as coal is replaced selectively by gas. Coal ceases to be important when the wind penetration level rises above $30 \%$. The prices for the GCC and GCT components at the $30 \%$ wind penetration 
level are equal to $6.01 \mathrm{c} / \mathrm{kWh}$ and $15.32 \mathrm{c} / \mathrm{kWh}$ respectively. Costs for electricity in the $\mathrm{CO}_{2}$ optimal model are only slightly higher than the costs for the price optimal model (less than $0.024 \mathrm{c} / \mathrm{kWh}$ ), too small to be resolved on the trend curve displayed in Figure $5 b$.

(a)

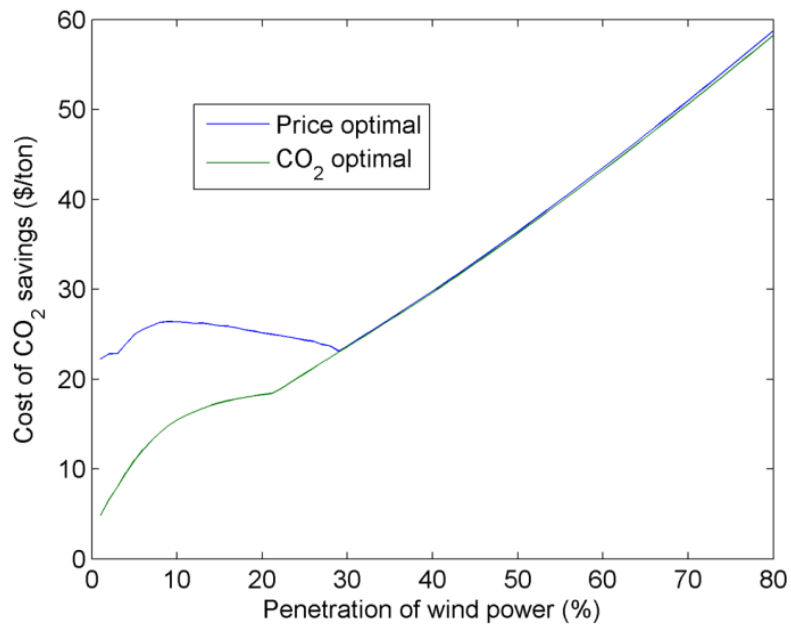

(b)

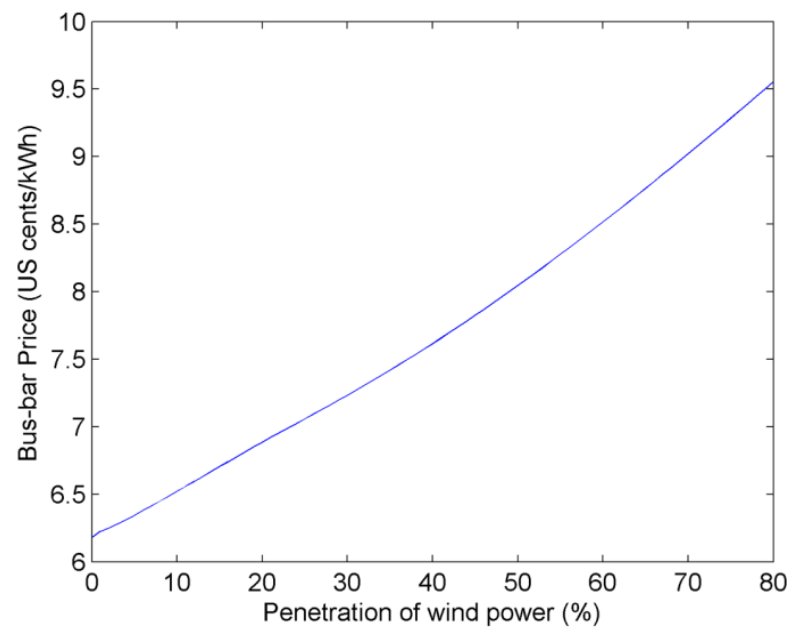

Figure 5 (a) Cost for $\mathrm{CO}_{2}$ savings as a function of wind penetration level for the price and $\mathrm{CO}_{2}$ optimal models. (b) System wide bus-bar price of electricity as a function of wind penetration level. Results for the price optimal and $\mathrm{CO}_{2}$ optimal models are indistinguishable given the resolution of the curve displaced. 
The estimates presented here for the costs related to the introduction into the 2030 ERCOT electricity system of different levels of wind depend obviously on the assumptions made concerning the expense for future coal and gas systems and for proposed new wind systems. Future (2030) prices for coal and gas were taken equal to $\$ 2 / \mathrm{MMBTU}$ and $\$ 6 / \mathrm{MMBTU}$ respectively. Projections of future prices for either coal or gas are subject however to significant uncertainty. Spot prices for natural gas, for example, have varied from a high of close to \$14/MMBTU to a low of less than \$4/ MMBTU over the past 5 years (21). Adding to the ambiguity relating to market related factors is the uncertainty associated with the possible introduction of a future tax on emissions of $\mathrm{CO}_{2}$. It is much easier to project costs for wind systems. We assumed here that electricity could be generated in 2030 using wind at a bus-bar price of $7 \mathrm{c} / \mathrm{kWh}$ reflecting experience with recent wind installations $(20,22)$. It could be argued however that with economies of scale, capital costs for wind systems might be expected to decline in the future. If costs for coal and gas should rise relative to the estimates assumed here and if prices for wind systems should decline (both possibilities judged as not unlikely), the expense for incorporation of wind in the future ERCOT system could switch readily from positive to negative.

As indicated in Figure 3, the quantity of electricity that could be generated using wind at high penetration levels (levels greater than about 40\%) could potentially exceed projected demand. We assigned zero value to this excess in the analysis presented above. It could be used, however, with electrolysis to produce $\mathrm{H}_{2}$, which could serve as 
a feedstock for production of nitrogen fertilizer, for methanol that could substitute for gasoline and diesel fuels in the transportation sector, or for a host of other useful chemical products (23-25). The problem is that since the supply of $\mathrm{H}_{2}$ contributed by the potential excess in electricity from wind would be necessarily intermittent, the costs associated with the electrolysis system would be prohibitive if the electrolysis system were supplied solely by the electricity from excess wind: the capacity factor for the electrolysis system would be necessarily very low. This complication could be avoided if electricity from conventional sources, specifically gas and nuclear, in addition to that from excess wind could be channeled to supply the demands of the projected electrolysis system. Further study to explore the feasibility of such an initiative, including its impact on the overall costs of electricity and the potential to accommodate further savings in emissions of $\mathrm{CO}_{2}$, would clearly be of value.

There are 11.5 million conventional gasoline and/or diesel powered motor vehicles registered currently in the state of Texas (26). Given present trends, it is likely that a significant fraction of the future (2030) motor vehicle fleet not only in Texas but also in the U.S. more generally will be powered at least in part by electricity. The battery pack of the Chevrolet Volt introduced recently by General Motors has the potential to store up to $8.8 \mathrm{kWh}$ of useful energy (27). If we assume that $20 \%$ of the current vehicle population could be represented by plug-in hybrids (PHEVs) or E-REVs by 2030, the batteries of these vehicles would have the capacity to store up to $20 \mathrm{GWh}$ of electricity, with the potential to generate important savings not only in the demand for oil but also in 
emissions of $\mathrm{CO}_{2}$ and to do so with a significant reduction in the cost of motoring.

To explore the potential benefits of a future fleet of PHEVs, we repeated the analysis of the electrical system described here assuming 2.25 million PHEV vehicles with properties similar to those advertised for the Chevrolet E-REV. We assumed that these vehicles would be charged at night when demand for electricity would normally be at a minimum, that individual vehicles would undergo a typical charge-discharge cycle over a 24 -hour period (28-29) and that $30 \%$ of the electricity stored in the vehicle battery packs could be returned to the grid during times of high demand during the day. This would result in an increase in the operational efficiency of the overall electrical system by smoothing out the normal differences in day/night demand for power, taking advantage further of the fact that the supply of electricity from wind is typically greater at night than during the day. The benefits of the proposed PHEV fleet would be particularly significant at higher levels of wind penetration. At a penetration level for wind of greater than $60 \%$, introduction of the proposed PHEV fleet could reduce the cost for $\mathrm{CO}_{2}$ savings by as much as $\$ 1.8$ per ton, with minimal impact on the overall cost for electricity (See SI).

This study assumed that the hourly variation in the growth of demand for electricity projected for ERCOT in 2030 should be similar to the pattern observed in 2006. It assumed further that the wind resources derived here for 2006 should apply at least approximately to conditions expected in the future (i.e. no significant change with time in either the strength or temporal/spatial variation of wind). As discussed earlier, 
our analysis is sensitive also to the specific assumptions made with respect to future prices not only for coal and gas but also for wind systems. An analysis of the sensitivity of results to assumptions concerning fuel prices, interest rates and targeted IRR is presented in SI.

Wind resources tend to peak in winter and at night when demand for electricity is typically at a minimum. A combination of wind and solar generated electricity would provide a better match of supply to demand $(15,16)$. The advantage of the complementarity between wind and solar would be offset however to some extent by the fact that solar source is currently more expensive than the source from wind. We propose to explore this issue further in a future study. 


\section{Acknowledgement}

The RUC-20 data were provided by NOAA\NCEP. We are indebted to Frederick H. Abernathy, James G. Anderson, Joseph Cullen, William W. Hogan, Nielsen Chris and Yu Lei for valuable discussions. The research was supported by the National Science Foundation, grant AGS-1019134. We thank three anonymous referees for their very helpful suggestions.

\section{Description of SI section:}

Potential hourly production of electricity from wind in the CREZ region of Texas is evaluated using assimilated meteorological data provided by NCEP. An economic model is applied to derive costs for incorporation of different levels of wind power in projected 2030 demand for electricity in Texas. 


\section{References}

(1) Hoogwijk, M.; Vries, B. d.; Turkenburg, W., Assessment of the global and regional geographical, technical and economic potential of onshore wind energy. Energy Economics 2004, 26, (5), 889-919.

(2) Archer, C. L.; Jacobson, M. Z., Evaluation of global wind power. J. Geophys. Res. 2005, 110, (D12), D12110.

(3) Lu, X.; McElroy, M. B.; Kiviluoma, J., Global potential for wind-generated electricity. Proc. Natl. Acad. Sci. USA 2009, 106, (27), 10933-10938.

(4) Boden, T.; Marland, G., Global $\mathrm{CO}_{2}$ Emissions from Fossil-Fuel Burning, Cement Manufacture, and Gas Flaring. In 1751-2007 June 8, 2010 ed.; Carbon Dioxide Information Analysis Center (CDIAC): 2010; $p 1$.

(5) Banunarayanan, V.; Miller, N.; Chahal, A.; Zandt, D. V.; Freeman, L.; Walling, M.; Martinez, J.; Walling, R. A. Analysis of Wind Generation Impact on ERCOT Ancillary Services Requirements; GE Energy: Fairfield, Connecticut, March 28, 2008, 2008; p 254.

(6) Katerina, D.; Jay, A.; B., L. L., Are renewables portfolio standards cost-effective emission abatement policy? Environ. Sci. Technol 2005, 39, (22), 8578-8583.

(7) Holttinen, $\mathrm{H}$.; Tuhkanen, S., The effect of wind power on $\mathrm{CO}_{2}$ abatement in the Nordic Countries. Energy Policy 2004, 32, (14), 1639-1652.

(8) Delarue, E. D.; Luickx, P. J.; D'haeseleer, W. D., The actual effect of wind power on overall electricity generation costs and $\mathrm{CO}_{2}$ emissions Energy Conversion and Management 2009, $50,(6), 1450-1456$.

(9) ERCOT Analysis of Potential Impacts of $\mathrm{CO}_{2}$ Emissions Limits on Electric Power Costs in the ERCOT Region; Electric Reliability Council of Texas: Austin, TX, May 12, 2009, 2009; p 35.

(10)Archer, C. L.; Jacobson, M. Z., Supplying Baseload Power and Reducing Transmission Requirements by Interconnecting Wind Farms. J. Appl. Meteor. Climatol. 2007, 46, (11), 1701-1717.

(11)Katzenstein, W.; Fertig, E.; Apt, J. The variability of interconnected wind plants; Carnegie Mellon Electricity Industry Center 2010; p 25.

(12) Holttinen, H., Hourly wind power variations in the Nordic countries. Wind Energy 2005, 8, (2), 173-195.

(13)Benjamin, S. G.; Brown, J. M.; Brundage, K. J.; Dévényi, D.; Grell, G. A.; Kim, D.; Schwartz, B. E.; Smirnova, T. G.; Smith, T. L.; Weygandt, S. S.; Manikin, G. S. RUC20- the 20-km version of the Rapid Update Cycle; National Oceanic and Atmospheric Administration (NOAA): Boulder, CO, April 11, 2002, 2002; p 30.

(14)ERCOT Long-Term Hourly Peak Demand and Energy Forecast; Electric Reliability Council of Texas: Austin, Texas, May 1, 2009, 2009; p 39.

(15)Jacobson, M. Z.; Delucchi, M. A., Providing all global energy with wind, water, and solar power, Part I: Technologies, energy resources, quantities and areas of infrastructure, and materials. Energy Policy 2010, in press.

(16)Delucchi, M. A.; Jacobson, M. Z., Providing all global energy with wind, water, and solar power, Part II: Reliability, system and transmission c osts, and policies. Energy Policy 2010, in press.

(17)US-EIA Electricity Market Module; U.S. Energy Information Administration: Washington, D.C., April 2010, 2010c; pp 89-107.

(18)Masters, G. M., Renewable and Efficient Electric Power Systems. A John Wiley \& Sons, Inc.: Hoboken, New Jersey, 2004. 
(19)US-EIA Electric Power Delivered Fuel Prices and Quality for Coal, Petroleum, Natural Gas, 1990 Through 2008 http://www.eia.doe.gov/cneaf/electricity/st_profiles/texas.html (March 10),

(20)Wiser, R.; Bolinger, M. 2008 Wind Technologies Market Report; DOE/GO-102009-2868; U.S. Department of Energy: Washington, D.C., JULY 2009, 2009; p 68.

(21)US-EIA Natural Gas Prices http://www.eia.doe.gov/dnav/ng/ng_pri_sum_dcu_nus_m.htm (July 1, 2010),

(22)Wiser, R.; Bolinger, M. Annual Report on U.S. Wind Power Installation, Cost and Performance Trends : 2007; U.S. Department of Energy: Washington, DC, May 2008, 2008; p 32.

(23)McElroy, M. B., Challenge of global climate change: Prospects for a new energy paradigm. Front. Environ. Sci. Engin. China 2010a, 4, (1), 2-11.

(24)McElroy, M. B., Energy Perspectives, Problems, and Prospects. Oxford University Press: New York, 2010b; $\mathrm{p} 409$.

(25)US-EIA The Impact of Increased Use of Hydrogen on Petroleum Consumption and Carbon Dioxide Emissions; U.S. Energy Information Administration: Washington, DC, August 2008, 2008; $p 84$.

(26)Texas-DMV Currently Registered Vehicle Regclasscd Totals, by County; Texas Department of Motor Vehicles: Austin, TX, 2010; p 256.

(27)Chevrolet Introducing Chevrolet Volt. http://www.chevrolet.com/volt/ (June 7, 2010),

(28)Kempton, W.; Archer, C. L.; Dhanju, A.; Garvine, R. W.; Jacobson, M. Z., Large $\mathrm{CO}_{2}$ reductions via offshore wind power matched to inherent storage in energy end-uses. Geophys. Res. Lett. 2007, 34, (2), 5.

(29)Parks, K.; Denholm, P.; Markel, T. Costs and Emissions Associated with Plug-In Hybrid Electric Vehicle Charging in the Xcel Energy Colorado Service Territory; U.S. National Renewable Energy Laboratory: Golden, Colorado, May 2007, 2007; p 29. 